\title{
COMMENTARY
}

\section{Fluids in septic shock: too much of a good thing?}

\author{
AB Johan Groeneveld* \\ See related research by Brandt et al., http://ccforum.com/content/13/6/R186
}

\begin{abstract}
In a recent issue of Critical Care, Brandt and colleagues report the effects of a 'liberal'fluid loading protocol compared to a more'restrictive' protocol on

hemodynamics and mortality in pigs in which septic shock had been induced. It appears that the former protocol was associated with higher mortality in spite of improved hemodynamics compared to the latter. The results of the paper are discussed here in view of the scope and mechanisms of these findings. With regard to fluid resuscitation, they indicate that too much of an otherwise good thing is harmful, even if overhydration and edema formation seem to have been prevented. They also do not exclude a specific toxic effect of the larger volumes of hydroxyethyl starch in the 'liberal' strategy. The precise nature of a toxic effect remains obscure, however, but may involve the kidneys.
\end{abstract}

\section{Introduction}

In a recent issue of Critical Care, Brandt and coworkers [1] performed fluid resuscitation on pigs with endotoxemia or fecal peritonitis using either moderate volumes of crystalloids $(10 \mathrm{ml} / \mathrm{kg} / \mathrm{h})$ or larger volumes of crystalloids supplemented by 130/0.4 hydroxyethyl starch (combined $20 \mathrm{ml} / \mathrm{kg} / \mathrm{h}$ ). These protocols were designed to mimic the relative 'restrictive' and 'liberal' fluid resuscitation policies that have been previously compared in human major surgery and acute lung injury/acute respiratory distress syndrome [2-4]. In both sepsis models, mortality increased with 'liberal' fluid loading protocols in spite of better haemodynamic stabilization. This interesting study raises a number of questions.

\section{Volume and type of fluid in the resuscitation from sepsis}

Although supplemental hydroxyethyl starch use in both study arms was partially 'goal-directed' - on the basis of

${ }^{*}$ Correspondence: johan.groeneveld@vumc.nl

Department of Intensive Care, Vrije Universiteit Medical Centre, De Boelelaan 1117, 1081 HV Amsterdam, The Netherlands cardiac output responses assessed by esophageal Doppler the doses used for fluid loading were relatively fixed rather than completely based on cardiac fluid responses (fluid responsiveness). The latter is preferable at the bedside, even if we do not formally know whether such therapy causes less morbidity and mortality in septic shock than using fixed volumes or guiding infusion according to relatively crude hemodynamics, such as the central venous pressure, as currently recommended [5]. It is likely, however, that tailored 'liberal' therapy decreases the risk for iatrogenic and detrimental fluid overload compared to fixed 'liberal' therapy [6-8]. The debate about fixed 'restrictive' versus 'liberal' versus 'goaldirected' therapy in the case of major surgery is also unresolved [2,3,9]. Differing results among studies, which may relate to differing case mixes, definitions, hemodynamic monitoring techniques/endpoints and treatment strategies, preclude unequivocal conclusions [9].

The authors used different types of fluid in the 'restrictive' and 'liberal' arms, with hydroxyethyl starch used particularly in the latter. A toxic effect of hydroxyethyl starch can not thus be ruled out, so it is possible that the higher mortality in the 'liberal' arm was caused, in part, by toxicity rather than large volumes. Indeed, mortality in the control non-septic pigs receiving the 'liberal' protocol was $13 \%$ ( 1 out of 8 ). Toxicity may include renal damage, as was particularly noted from the histology of the 'liberal' endotoxin-challenged animals. In any case, the histology of several tissues suggested that overhydration and (pulmonary) edema had not increased in the 'liberal' compared to the 'restrictive' fluid loading groups, even in the presence of so-called colloid plaques observed in lungs, for instance, although the nature of these remains relatively unclear. Finally, starch preparations may have multiple anti-inflammatory effects, but we do not know whether this is good or bad during sepsis [10]. Collectively, the experiments reported raise the interesting idea that too much of a good thing is detrimental, whether related to relative overtreatment or to toxicity of the hydroxyethyl starch colloid.

A comparison of these experimental results with the literature is difficult because of, for example, highly varying study goals and endpoints. Morisaki and colleagues [11] found that starches (more so than Ringers lactate) 
ameliorated progression of microvascular and parenchymal injury during the development of peritonitis in sheep. Su and colleagues [12] noted that starch, albumin, gelatin and Ringers lactate fluid resuscitation afforded similar survival benefits during protracted fecal peritonitis in sheep, in spite of greater hemodynamic effects with the first two. This illustrates that the current data provided by Brandt and colleagues [1] may need to be confirmed. The observations that hemodynamic and mortality endpoints may not go in the same direction also deserve further explanation.

\section{Clinical implications}

What are the clinical implications of these experimental results? The potential but unconfirmed (renal) toxicity of hydroxyethyl starch is indeed a subject of ongoing research in human septic shock and the current experimental observations may further fuel these efforts [13-15]. For instance, the potential renal toxicity of starch preparations may depend on volume, type, substitution of starch and the underlying condition of patients in whom fluids are infused, so that general conclusions are hard to draw at this stage [13-15]. That colloids have greater hemodynamic effects, for a given fluid infusion volume, than crystalloids, even in sepsis with increased permeability and potential leakage of the compounds, is corroborated by recent clinical observations [16].

\section{Conclusion}

The outcome benefits and drawbacks of fluid resuscitation in sepsis and shock may not solely relate to hemodynamic effects, so that more is not always better, even if overt overhydration and (pulmonary) edema do not occur. The experimental findings remind us that outcome may also be a matter of the type of fluid used for initial resuscitation during septic shock. Obviously, this relates, among other factors, to the increasing evidence that starch solutions have important side effects, particularly when exceeding recommended maximum daily doses. Further comparative research is needed.

\section{Competing interests}

The author declares that he has no competing interests.

Published: 19 January 2010

\section{References}

1. Brandt S, Regueira T, Bracht H, Porta F, Djafarzadeh S, Takala J, Gorrasi J, Borotto E, Krejci V, Hiltebrand LB, Bruegger LE, Beldi G, Wilkens L, Lepper PM, Kessler U, Jakob SM. Effect of fluid resuscitation on mortality and organ function in experimental sepsis models. Crit Care 2009, 13:R186
2. Giglio MT, Marucci M, Testini M, Brienza N: Goal-directed haemodynamic therapy and gastrointestinal complications in major surgery: a metaanalysis of randomized controlled trials. Br J Anaesth 2009, 103:637-646.

3. Rahbari NN, Zimmermann JB, Schmidt T, Koch M, Weigand MA, Weitz J: Metaanalysis of standard, restrictive and supplemental fluid administration in colorectal surgery. Br J Surg 2009, 96:331-341.

4. Stewart RM, Park PK, Hunt JP, McIntyre RC Jr, McCarthy J, Zarzabal LA, Michalek JE; National Institutes of Health/National Heart, Lung, and Blood Institute Acute Respiratory Distress Syndrome Clinical Trials Network: Less is more: improved outcomes in surgical patients with conservative fluid administration and central venous catheter monitoring. J Am Coll Surg 2009, 208:725-735

5. Dellinger RP, Levy MM, Carlet JM, Bion J, Parker MM, Jaeschke R, Reinhart K, Angus DC, Brun-Buisson C, Beale R, Calandra T, Dhainaut JF, Gerlach H, Harvey M, Marini JJ, Marshall J, Ranieri M, Ramsay G, Sevransky J, Thompson BT, Townsend S, Vender JS, Zimmerman JL, Vincent JL; International Surviving Sepsis Campaign Guidelines Committee; American Association of CriticalCare Nurses; American College of Chest Physicians; American College of Emergency Physicians; Canadian Critical Care Society; European Society of Clinical Microbiology and Infectious Diseases; European Society of Intensive Care Medicine; et al.: Surviving Sepsis Campaign: international guidelines for management of severe sepsis and septic shock: 2008. Crit Care Med 2008, 36:296-327.

6. Alsous F, Khamiees M, DeGirolamo A, Amoateng-Adjepong Y, Manthous CA: Negative fluid balance predicts survival in patients with septic shock: a retrospective pilot study. Chest 2000, 117:1749-1754.

7. Groeneveld $A B$, Polderman $\mathrm{KH}$ : Acute lung injury, overhydration or both? Crit Care 2005, 9:136-137.

8. Sakr Y, Vincent JL, Reinhart K, Groeneveld J, Michalopoulos A, Sprung CL, Artigas A, Ranieri VM; Sepsis Occurence in Acutely III Patients Investigators: High tidal volume and positive fluid balance are associated with worse outcome in acute lung injury. Chest 2005, 128:3098-3108.

9. Bundgaard-Nielsen $M$, Secher $N H$, Kehlet H: 'Liberal' vs. 'restrictive' perioperative fluid therapy - a critical assessment of the evidence. Acta Anaesthesio/ Scand 2009, 53:843-851.

10. Matharu NM, Butler LM, Rainger GE, Gosling P, Vohra RK, Nash GB: Mechanisms of the anti-inflammatory effects of hydroxyethyl starch demonstrated in a flow-based model of neutrophil recruitment by endothelial cells. Crit Care Med 2008, 36:1536-1542.

11. Morisaki H, Bloos F, Keys J, Martin C, Neal A, Sibbald WJ: Compared with crystalloid, colloid therapy slows progression of extrapulmonary tissue injury in septic sheep. J App/ Physiol 1994, 77:1507-1518.

12. Su F, Wang Z, Cai Y, Rogiers P, Vincent $J$ : Fluid resuscitation in severe sepsis and septic shock: albumin, hydroxyethyl starch, gelatin or Ringer's lactatedoes it really make a difference? Shock 2007, 27:520-526.

13. Brunkhorst FM, Engel C, Bloos F, Meier-Hellmann A, Ragaller M, Weiler N, Moerer O, Gruendling M, Oppert M, Grond S, Olthoff D, Jaschinski U, John S, Rossaint R, Welte T, Schaefer M, Kern P, Kuhnt E, Kiehntopf M, Hartog C, Natanson C, Loeffler M, Reinhart K, German Competence Network Sepsis (SepNet): Intensive insulin therapy and pentastarch resuscitation in severe sepsis. N Engl J Med 2008, 358:125-139.

14. Wiedermann C: Systematic review of randomized clinical trials on the use of hydroxyethyl starch for fluid management in sepsis. BMC Emerg Med 2008, 8:1-8.

15. Boldt J. PRO: hydroxyethylstarch can be safely used in the intensive care patient-the renal debate. Intensive Care Med 2009, 35:1331-1336.

16. Trof RJ, Sukul SP, Twisk JWR, Girbes ARJ, Groeneveld ABJ: Greater cardiac response of colloid than saline fluid loading in septic and non-septic critically ill patients with clinical hypovolaemia. Intensive Care Med, in press.

doi:10.1186/cc8201

Cite this article as: Groeneveld ABJ: Fluids in septic shock: too much of a good thing? Critical Care 2010, 14:101. 